\title{
Acute and overuse injuries among sports club members and non-members: the Finnish Health Promoting Sports Club (FHPSC) study
}

\author{
L. Ristolainen ${ }^{1 *}$ (D) K. Toivo ${ }^{2}$, J. Parkkari², S. Kokko ${ }^{3}$, L. Alanko ${ }^{4}$, O. J. Heinonen ${ }^{5}$, R. Korpelainen ${ }^{6,7,8}$, K. Savonen $^{9,10}$, \\ H. Selänne ${ }^{11}$, T. Vasankari ${ }^{12}$, L. Kannas ${ }^{3}$, J. Villberg ${ }^{3}$ and U. M. Kujala ${ }^{3}$
}

\begin{abstract}
Background: Physical activity in adolescence is promoted for its multi-dimensional health benefits. However, too intensive sports participation is associated with an increased injury risk. Our aim was to compare the occurrence of acute and overuse injuries in Finnish sports club members and non-members and to report training and competing habits associated with a higher injury risk in sports club members.

Methods: In this cross-sectional survey targeted at 14-16-year-old adolescents, a structured questionnaire was completed by 1077 sports club members and 812 non-members. The main outcome measures were self-reported acute and overuse injuries, their location and type.

Results: At least one acute injury in the past year was reported by $44.0 \%$ of sports club members and $19.8 \%$ of non-members $(P<0.001)$. The sex-adjusted odds ratio $(\mathrm{OR})$ for acute injury in sports club members compared to non-members was 3.13 (95\% confidence interval (95\% Cl) 2.54-3.87). Thirty-five percent of sports club members and $17.4 \%$ of non-members $(P<0.001)$ reported at least one overuse injury during the past year. The overuse injury OR for sports club members was 2.61 (95\% Cl 2.09-3.26). Sports club members who trained $7-14 \mathrm{~h}$ per week during training (OR 1.61, 95\% Cl 1.21-2.12, $P=0.001$ ) or competition season (OR 1.55, 95\% Cl 1.18-2.06, $P=0.002$ ) were more likely to report an injury compared to members who trained $3-6 \mathrm{~h}$ per week. Those sports club members who participated in forty competitions or more compared to 7-19 competitions per year were more likely to report an acute injury (OR $1.55,95 \% \mathrm{Cl} 1.05-2.08, P=0.028)$ or for an overuse injury (OR 1.53, 95\% Cl 1.02-2.30, $P=0.038)$.

Conclusions: Both acute and overuse injuries are common among youth sports club members, and the number increases along with increasing amounts of training and competitions. More effective injury prevention is needed both for adolescents engaging in sports club activities and for other adolescents.
\end{abstract}

Keywords: Athletic injury, Acute injury, Overuse injury, Adolescent, Sports club member, Non-member

\footnotetext{
* Correspondence: leena.ristolainen@hotmail.fi

'Orton Orthopaedic Hospital, Orton, Helsinki, Finland

Full list of author information is available at the end of the article
}

(c) The Author(s). 2019 Open Access This article is distributed under the terms of the Creative Commons Attribution 4.0 International License (http://creativecommons.org/licenses/by/4.0/), which permits unrestricted use, distribution, and reproduction in any medium, provided you give appropriate credit to the original author(s) and the source, provide a link to the Creative Commons license, and indicate if changes were made. The Creative Commons Public Domain Dedication waiver (http://creativecommons.org/publicdomain/zero/1.0/) applies to the data made available in this article, unless otherwise stated. 


\section{Background}

Physical activity in adolescence provides multidimensional health benefits $[1,2]$. However, the risk of sports injuries increases along with the increasing volume, intensity, and competitiveness of the sports activities [3]. Youth team sports carry a higher injury risk than individual sports [4]. Some earlier studies have focused only on acute [5] or overuse injuries [6] only on either sex [7, 8] or on a specific injury, such as anterior cruciate ligament rupture $[9,10]$. There are scattered studies on adolescents covering various different sports and different types of injuries. The occurrence and risk factors of different types of unintentional injuries among Finnish adolescents have previously been studied [11]. The sports injuries of adolescent sports club members have been studied previously [12-14], but studies comparing injuries between sports club members and non-members are rare [13]. Furthermore, the occurrence of overuse injuries has been studied less than that of acute injuries. The American Medical Society for Sports Medicine has made a position statement concerning overuse injuries and burnout, which are common problems in youth sports [15].

Sports clubs are a common way to participate in organized sports in Finland. Nearly half of the adolescent population reported to participate in organized sports in year 2013 [16] and according to the newest report this has raised to as much as 62\% [17]. This cross-sectional study is a part of the Finnish Health Promoting Sports Club (FHPSC) study [18]. The purpose of this report is to compare the occurrence of self-reported acute and overuse injuries in Finnish adolescent sports club members and non-members. We also compared the anatomic locations of acute and overuse injuries and the injury types and studied the association between training and competing habits with the risk of injury. The injury definitions used in the questionnaire were obtained from an earlier Finnish study [19]. An acute injury was defined as an injury occurring suddenly keeping one away from exercise for at least one day or requiring a physician's care $[20,21]$. An overuse injury was defined as an injury that causes gradually increasing pain during exercise loading without any noticeable external cause possibly stopping exercise completely [20,22].

\section{Methods}

\section{The FHPSC study}

The aim of the FHPSC study was to survey health promotion orientation and activity of youth sports clubs and coaches. In addition to surveys, a clinical health examination was performed and the health behavior and health status of youth participating in sports clubs was compared to their non-participating peers.

\section{Data collection}

The FHPSC data were collected during 2013 in two rounds, from January to May for winter sports, and from August to December for summer sports. The comparison data for non-members were collected accordingly in two rounds via schools (9th grade, 14-16-year-old adolescents). For more details, see Kokko et al. [18].

\section{Participants \\ The sports club sample}

To obtain a nationally representative sample a total of 240 youth sports clubs from the ten most popular sports disciplines for youth were targeted. Sports clubs were stratified by the following criteria: 1) winter and summer sports, and 2) team and individual sports. Thereafter, the most popular disciplines (basketball, cross-country skiing, floorball, gymnastics, ice hockey, orienteering, skating, soccer, swimming, and track and field) were chosen. The main sports of the sports club members are shown in Additional file 1: Table S1. In total, 1077 youth sports club members (a participation rate of $64 \%$ ) were included (Fig. 1).

\section{The school-based sample}

To compare the acute and overuse injuries of youths participating in organized sports clubs (i.e., members) with their non-participating counterparts (i.e., non-members) separate data were collected via schools. These data were also collected in two rounds (winter and summer). Overall, 159 schools were contacted and 100 participated (63\%). Members of the school-based sample $(n=1648)$ were asked about their sports club participation, and sports club members in the school data $(n=458)$ were treated as sports club members in the following analysis. The final study sample included 812 non-members and 1077 sports club members (Fig. 1).

\section{Surveys}

Two surveys were conducted for all participants. The first survey focused on the health behaviors, including self-evaluated physical activity. The second survey focused on the adolescents' injuries and musculoskeletal health, and these questions were identical for both groups. The questions used in the surveys were compiled from previously validated questionnaires (Additional file 2: Table S2) [19, 23-26].

In the injury questionnaire the participants reported the number of acute and overuse injuries they had suffered within the preceding twelve months, the location of the injury, the type of injury, and the circumstances under which they occurred. Additional questions concerning the main sport and training habits were directed to sports club members. Participants who responded to the injury-questionnaire $(n=1797,95 \%)$ also responded 


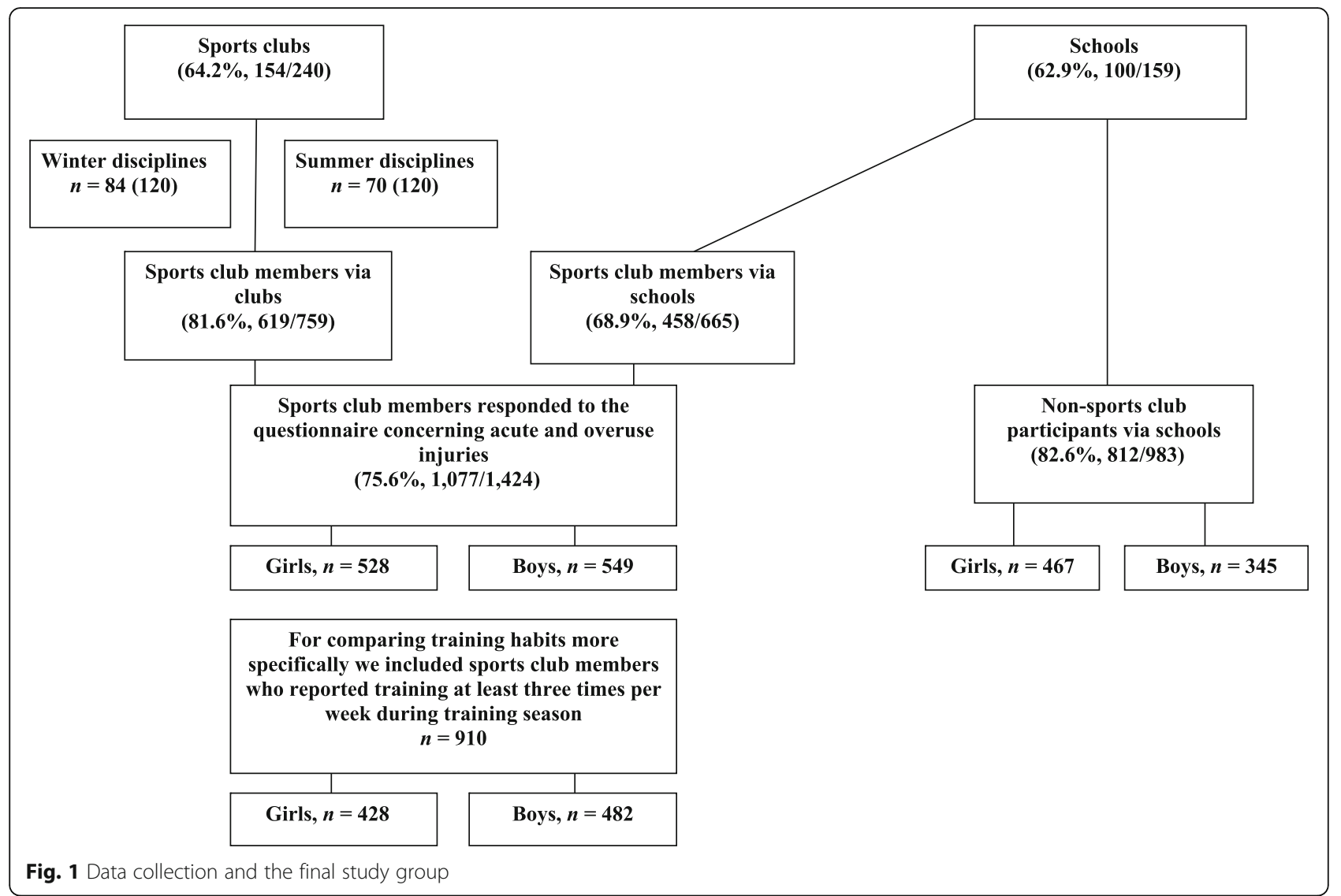

to a questionnaire on leisure-time physical activity [18]. For more details of the structured questionnaire, see Additional file 2: Table S2. We used the question "How many hours of vigorous exercise/physical activity do you usually do per week in your leisure time (after school lessons)" for both groups to assess the amount of physical activity in order to compare the effect of the physical activity level on the acute or overuse injury risk [27].

"The term "acute injury" was defined as an acute sports injury which occurs suddenly or accidentally interrupting exercise or causing an identifiable trauma, and keeps one away from exercise for at least one day, or requires a physician's care. The term "overuse injury" was defined as an injury that causes increasing pain during or after exercise without any noticeable external cause of injury and possibly even completely prevents exercise" [19-22].

The study is carried out in conformance with the declaration of Helsinki. A positive statement from the Ethics Committee of Health Care District of Central Finland was received (record number $23 \mathrm{U} / 2012$ ). All sports clubs participated free-willingly to the study. This was secured by requesting clubs permission at the beginning of study. Thereafter, all adult respondents were notified that they had a right to refuse to participate and withdraw from the study at any time.

\section{Statistical analysis}

Differences between sports club members and nonmembers were assessed using crosstabs and the chi-squared test and $t$-test when appropriate. Logistic regression was applied to study the associations between injuries (acute and overuse) and sports club membership and sex. Odds ratios (ORs) and their 95\% CIs (95\% Confidence Intervals) were calculated for the occurrence of acute and overuse injuries, anatomic location, and type of injuries in sports club members compared to nonmembers and the logistic regression analysis was adjusted for sex. Logistic regression analysis was also applied to study the associations between the injuries and the characteristics of training and competing among the sports club members. Odds ratios and their 95\% CIs were also calculated for the occurrence of acute and overuse injury (at least one injury) by sports club participation and by volume of reported leisure-time physical activity, the logistic regression analysis was adjusted for sex. We also more specifically compared the occurrence of acute and overuse injuries and their anatomic location between sports club members training three times per 
Table 1 At least one acute, one overuse injury or at least one acute or overuse injury among sports club members and nonmembers

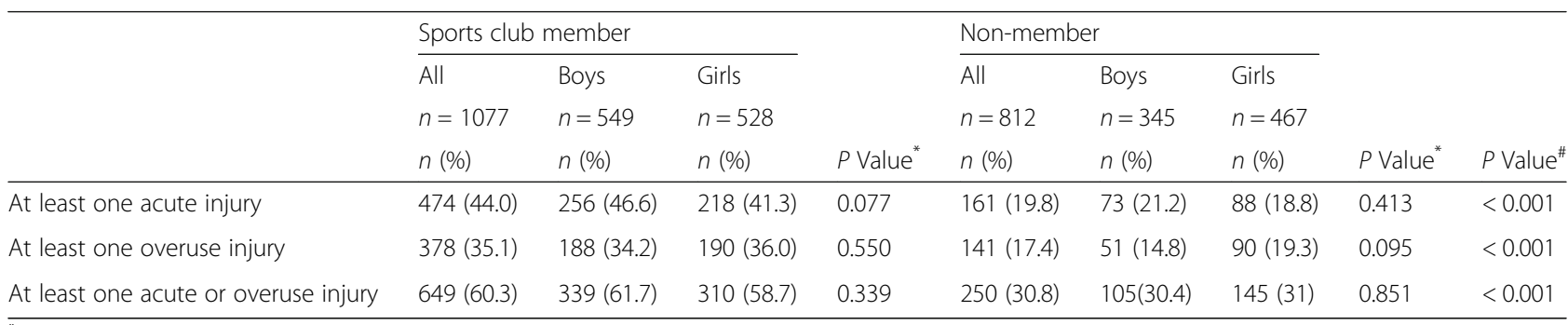

${ }^{*} P$ Values for statistical difference for the occurrence of injuries between boys and girls among sports club members and non-members

${ }^{\#} P$ Values for statistical difference for the occurrence of injuries between all sports club members and non-members derived from logistic regression analysis adjusted for sex

week or more in the training season $(n=910)$ and non-members $(n=812)$. The statistically significant threshold was accepted at $P \leq 0.05$ (two-tailed). IBM SPSS Statistics (version 22.0) was used to carry out all analyses except the total number of acute and overuse injuries and injury rates in different anatomical locations.

\section{Results}

Fifty-one percent of sports club members (549 of 1077 ) and $42.5 \%$ (345 of 812 ) of non-members were boys $(P<0.001$; Fig. 1$)$. Eighty-four percent $(n=910$ : 428 boys and 482 girls) of sports club members reported training at least three times weekly during the training season in the past year.

\section{Occurrence of acute and overuse injuries}

The total number of reported acute injuries in adolescents within the past 12 months was 2478 (Table 1). Forty-four percent of sports club members and $19.8 \%$ of non-members $(P<0.001)$ reported at least one acute injury in the past twelve months (Table 1). Boys were more likely to report acute injuries than girls (club membership-adjusted OR 1.31, 95\% CI 1.08-1.59, P $=0.006$ ). Among sports club members, individual sports' participants were less likely to report an acute injury than team and contact sports participants (OR 0.59, 95\% CI $0.37-0.65, P<0.001)$. In the sub-group of sports club members training at least three times weekly during the training season, compared to non-members, the sex adjusted OR for reporting at least one acute injury was 3.49 (95\% CI 2.81-4.34, $P<0.001$ ).

The total number of reported overuse injuries within the past 12 months was 1646. Thirty-five percent of sports club members and $17.4 \%$ of non-members $(P<0.001)$ reported at least one overuse injury during the past twelve months (Table 1). The difference between boys and girls was not statistically significant for reporting at least one overuse injury. Compared to the non-members, among the sub-group of sports club members training at least three times weekly during the training season, the sex-adjusted OR for reporting at least one overuse injury was 2.84 (95\% CI 2.26-3.56, $P<0.001$ ).

Sixty percent of sports club members and $30.8 \%$ of non-members reported either an acute or an overuse injury during past year (sex-adjusted $P<0.001$ ). For more details, see Table 1.

\section{Injuries by anatomic location}

Out of the 1790 acute injuries reported by sports club members the most (13.6\%) were injuries of the wrist or hand. This was also the most common acute injury location for non-members (15.1\%). The second most common location was the ankle for sports club members and knee for non-members (11.7 and $11.0 \%$ respectively) (Table 2). The third most common location for an acute injury in both groups was the foot, $11.5 \%$ of all acute injuries for sports club members and 9.9\% for non-members were injuries of the foot (Table 2).

The most common overuse injury location was the knee for sports club members $(16.8 \%$ out of all overuse injuries in sports club members), this was the third most common location for non-members (11.1\%). The second most common location for overuse injury was the hip, groin, gluteal and pelvis area for sports club members (11.1\%) followed by the wrist and hand (10.0\%). The most common location for an overuse injury for non-sports club members was the wrist or hand (Table 2).

The distributions of at least one injury by sports club membership, anatomic location, and sex are shown in Additional file 3: Table S3 for acute injuries and in Additional file 4: Table S4 for overuse injuries. Additional file 5: Table S5 shows the sex-adjusted details of at least one acute or overuse injury and its location in sports club members training more than three times compared to non-members.

\section{Injury types}

The most common acute injuries in both groups were sprains $31.6 \%$ of sports club members reported a sprain 
Table 2 The total number of acute and overuse injuries and percentages (\%) in different anatomical locations among sports club members and non-members

\begin{tabular}{|c|c|c|c|c|c|c|c|c|c|c|c|c|}
\hline & \multicolumn{3}{|c|}{ Sports club members $(n=1.077)$} & \multicolumn{3}{|c|}{ Non-members $(n=812)$} & \multirow{2}{*}{\multicolumn{3}{|c|}{$\frac{\text { Sports club members }(n=1.077)}{\text { Number of overuse injuries }}$}} & \multicolumn{3}{|c|}{ Non-members $(n=812$} \\
\hline & \multicolumn{6}{|c|}{ Number of acute injuries } & & & & & & \\
\hline & $n$ & $\% *$ & $\% * *$ & $n$ & $\%^{*}$ & $\% * *$ & $n$ & $\% *$ & $\% * *$ & $n$ & $\%^{*}$ & $\%^{* *}$ \\
\hline Head & 49 & 4.5 & 2.7 & 20 & 2.5 & 2.9 & & & & & & \\
\hline Face. teeth. Eye area & 79 & 7.3 & 4.4 & 32 & 3.9 & 4.7 & & & & & & \\
\hline Shoulder. upper arm. Clavicle & 121 & 11.2 & 6.8 & 44 & 5.4 & 6.4 & 46 & 4.3 & 4.3 & 32 & 3.9 & 5.5 \\
\hline Elbow. forearm & 58 & 5.4 & 3.2 & 29 & 3.6 & 4.2 & 33 & 3.1 & 3.1 & 21 & 2.6 & 3.6 \\
\hline Wrist and hand & 244 & 22.7 & 13.6 & 104 & 12.8 & 15.1 & 106 & 9.8 & 10.0 & 75 & 9.2 & 12.8 \\
\hline Neck. neck region & 66 & 6.1 & 3.7 & 35 & 4.3 & 5.1 & 46 & 4.3 & 4.3 & 38 & 4.7 & 6.5 \\
\hline Upper back & 35 & 3.2 & 2.0 & 19 & 2.3 & 2.8 & 29 & 2.7 & 2.7 & 20 & 2.5 & 3.4 \\
\hline Low back & 85 & 7.9 & 4.7 & 38 & 4.7 & 5.5 & 94 & 8.7 & 8.9 & 42 & 5.2 & 7.2 \\
\hline Chest & 33 & 3.1 & 1.8 & 19 & 2.3 & 2.8 & 18 & 1.7 & 1.7 & 12 & 1.5 & 2.0 \\
\hline Abdomen & 29 & 2.7 & 1.6 & 17 & 2.1 & 2.5 & 15 & 1.4 & 1.4 & 13 & 1.6 & 2.2 \\
\hline Hip. groin. Gluteals. pelvis & 182 & 16.9 & 10.2 & 53 & 6.5 & 7.7 & 118 & 11.0 & 11.1 & 61 & 7.5 & 10.4 \\
\hline Thigh & 109 & 10.1 & 6.1 & 32 & 3.9 & 4.7 & 80 & 7.4 & 7.6 & 37 & 4.6 & 6.3 \\
\hline Knee & 170 & 15.8 & 9.5 & 76 & 9.4 & 11.0 & 178 & 16.5 & 16.8 & 65 & 8.0 & 11.1 \\
\hline Calf and shin & 79 & 7.3 & 4.4 & 30 & 3.7 & 4.4 & 94 & 8.7 & 8.9 & 38 & 4.7 & 6.5 \\
\hline Ankle & 210 & 19.5 & 11.7 & 57 & 7.0 & 8.3 & 70 & 6.5 & 6.6 & 46 & 5.7 & 7.8 \\
\hline Achilles tendon & 35 & 3.2 & 2.0 & 15 & 1.8 & 2.2 & 28 & 2.6 & 2.6 & 18 & 2.2 & 3.1 \\
\hline Foot & 206 & 19.1 & 11.5 & 68 & 8.4 & 9.9 & 104 & 7.8 & 9.8 & 69 & 8.5 & 11.8 \\
\hline All injuries & 1790 & & & 688 & & & 1059 & & & 587 & & \\
\hline
\end{tabular}

* percentage of sports club members and non-members having sustained an injury in this anatomical area ${ }^{* *}$ percentage of the injuries in each area out of all acute or overuse injuries among sports club members and non-members

during the past 12-month, compared to $13.5 \%$ of non-members $(P<0.001)$. Contusions/bruises other than the head were the second most common type of injury in both groups (sports club members $17.1 \%$ vs. non-members $7.6 \%, P<0.001)$. The third most common acute injury type in sports club members was a muscle injury, and it was reported more often by members than non-members (13.5\% vs. $4.7 \%)$. Out of non-members, $4.8 \%$ reported sustaining a fracture within the past year, this being the third most common type of acute injury for this group.

The most common overuse injury type was muscle injury among both sports club members and non-members $(16.6 \%$ of sports club members and $10.1 \%$ of non-members reported at least one muscle injury, $P<$ $0,001)$. Overuse injuries of the bone were more prevalent among sports club members than non-members (9.8\% vs. $4.7 \%, P<0.001)$. However, no statistically significant difference was seen in stress fractures between sports club members and non-members $(2.9 \%$ vs. $1.6 \%, P=0.075$ ).

\section{Circumstances and causes of acute injuries}

The most common setting for acute injuries in sports club members was organized training (25.4\%) followed by matches or competitions (22.2\%). Among sports club members, acute injuries in matches or competitions were more common in boys than girls $(27.7 \%$ vs. $16.5 \%$, $P<0.001)$. There was no difference between sports club members and non-members in acute injuries occurring during leisure time activities (16.0\% vs. $17.1 \%)$ or school sports $(7.4 \%$ vs. $7.0 \%)$. Among non-members, boys were more likely to report an acute injury during leisure time activities than girls $(21.2 \%$ vs. $14.1 \%, P=0.028)$. In both groups, the main cause for an acute injury was falling/ stumbling (sports club members $16.8 \%$ vs. non-members $10.3 \%, P<0.001)$. In sports club members, other common reasons for an acute injury were tackling $(11.0 \%$ vs. $2.3 \%, P<0.001$ compared to non-members) and running (10.3\% vs. $4.3 \%, P<0.001)$.

\section{Training habits and injuries in sports club members}

For those with training history for more than five years, training at least twice a week, the sex-adjusted OR for an acute injury was 1.38 compared to those who had trained actively for $0-4$ years $(P=0.029$; Table 3$)$. Adolescents with weekly training for $7-14 \mathrm{~h}$ during the training season were 1.61 fold more likely to report an acute injury $(P=0.001)$ compared to adolescents who trained 3-6h per week. 
Table 3 Odds ratios (ORs) for at least one acute injury during the past twelve months in sports club members

\begin{tabular}{|c|c|c|c|c|c|c|c|c|c|}
\hline \multirow[b]{3}{*}{ Training Characteristics } & \multirow{2}{*}{\multicolumn{3}{|c|}{ All $(n=1077)$}} & \multicolumn{3}{|c|}{ Sports club members } & \multirow[b]{3}{*}{ OR } & \multirow{2}{*}{\multicolumn{2}{|c|}{ Girls $(n=528)$}} \\
\hline & & & & \multicolumn{3}{|c|}{ Boys $(n=549)$} & & & \\
\hline & $\mathrm{OR}^{*}$ & $95 \% \mathrm{Cl}$ & $P$ Value\# & $\mathrm{OR}$ & $95 \% \mathrm{Cl}$ & $P$ Value & & $95 \% \mathrm{Cl}$ & $P$ Value $^{\mathrm{x}}$ \\
\hline \multicolumn{10}{|l|}{ Main sports } \\
\hline Team and contact sports & 1.0 & & & 1.0 & & & 1.0 & & \\
\hline Individual sports & 0.59 & $0.37-0.65$ & $<0.001$ & 0.45 & $0.28-0.72$ & 0.001 & 0.70 & $0.48-1.01$ & 0.059 \\
\hline \multicolumn{10}{|l|}{ Starting training (age) } \\
\hline $4-7$ years old & 1.0 & & & 1.0 & & & 1.0 & & \\
\hline 8-11 years old & 0.99 & $0.76-1.31$ & 0.978 & 0.82 & $0.56-1.20$ & 0.305 & 1.24 & $0.82-1.86$ & 0.304 \\
\hline $12-15$ years old & 0.60 & $0.42-0.85$ & 0.004 & 0.59 & $0.36-0.97$ & 0.037 & 0.65 & $0.39-1.07$ & 0.090 \\
\hline \multicolumn{10}{|c|}{ Active training years at least 2 times/week } \\
\hline $0-4$ years & 1.0 & & & 1.0 & & & 1.0 & & \\
\hline $5-8$ years & 1.38 & $1.03-1.83$ & 0.029 & 1.55 & $1.01-2.37$ & 0.045 & 1.24 & $0.84-1.83$ & 0.274 \\
\hline $9-11$ years & 1.84 & $1.31-2.58$ & $<0.001$ & 1.89 & $1.19-2.98$ & 0.007 & 1.88 & $1.13-3.14$ & 0.016 \\
\hline \multicolumn{10}{|c|}{ Training hours per week during training season } \\
\hline $3-6 \mathrm{~h} /$ week & 1.0 & & & 1.0 & & & 1.0 & & \\
\hline 7-14 h/week & 1.61 & $1.21-2.12$ & 0.001 & 1.57 & $1.06-2.32$ & 0.025 & 1.65 & $1.11-2.45$ & 0.014 \\
\hline $15 \mathrm{~h}$ or more/week & 2.12 & $1.42-3.15$ & $<0.001$ & 2.16 & $1.28-3.64$ & 0.004 & 2.04 & $1.10-3.76$ & 0.023 \\
\hline \multicolumn{10}{|c|}{ Training hours per week during competition season } \\
\hline 3-6 h/week & 1.0 & & & 1.0 & & & 1.0 & & \\
\hline 7-14 h/week & 1.55 & $1.18-2.06$ & 0.002 & 1.39 & $0.94-2.04$ & 0.097 & 1.77 & $1.17-2.67$ & 0.006 \\
\hline $15 \mathrm{~h}$ or more/week & 1.78 & $1.20-2.63$ & 0.004 & 1.67 & $0.99-2.81$ & 0.055 & 1.91 & $1.05-3.48$ & 0.033 \\
\hline \multicolumn{10}{|c|}{ The amount of competitions during last 12 months } \\
\hline 7-19 competitions & 1.0 & & & 1.0 & & & 1.0 & & \\
\hline 20-39 competitions & 1.34 & $0.93-1.92$ & 0.118 & 1.48 & $0.89-2.47$ & 0.132 & 1.29 & $0.77-2.15$ & 0.331 \\
\hline 40 competitions or more & 1.55 & $1.05-2.28$ & 0.028 & 2.02 & $1.21-3.37$ & 0.007 & 0.92 & $0.48-1.77$ & 0.809 \\
\hline \multicolumn{10}{|c|}{ Resting days per week during training season } \\
\hline 3 resting days/week & 1.0 & & & 1.0 & & & 1.0 & & \\
\hline 2 resting days/week & 1.13 & $0.79-1.59$ & 0.507 & 1.25 & $0.77-2.02$ & 0.371 & 1.00 & $0.61-1.67$ & 0.977 \\
\hline 1 resting day/week & 1.35 & $0.95-1.93$ & 0.098 & 1.54 & $0.94-2.53$ & 0.088 & 1.18 & $0.70-1.96$ & 0.538 \\
\hline 0 resting day/week & 1.62 & $0.61-4.26$ & 0.333 & 1.30 & $0.36-4.78$ & 0.688 & 2.16 & $0.49-9.53$ & 0.310 \\
\hline
\end{tabular}

* OR = Odds Ratio, $95 \% \mathrm{Cl}=95 \%$ Confidence Interval

"P Values in all sports club members derived from logistic regression adjusted for sex

${ }^{\S} P$ Values in boys derived from logistic regression

a $P$ Values in girls derived from logistic regression

Sports club members participating in 40 competitions or more per year were more likely to report an acute injury $(P=0.028)$ compared to those having $7-19$ competitions a year. This was seen particularly among boys $(P=0.007)$ but not among girls $(P=0.809$; Table 3$)$. The mean amount of competitions during the past twelve months was higher among boys than girls (30.1 vs. $15.1, P<0.001$ ).

Having an overuse injury was 1.63 fold more likely $(P=0.001)$ in adolescents who trained $7-14 \mathrm{~h}$ weekly during the preceding training season compared to those training $3-6 \mathrm{~h}$. Those adolescents participating in 40 competitions or more per year were significantly more likely to report an overuse injury in all adolescents $(P=0.038)$ compared to those participating in 7-19 competitions (Table 4).

\section{Overall leisure-time physical activity and injuries by sport club membership}

The distributions of leisure-time physical activity between sports club members and non-members is shown in Additional file 6: Table S6. We found that the probability of an acute injury for those who reported "physical activity for about $30 \mathrm{~min}$ per week" 
Table 4 Odds ratios (ORs) for at least one overuse injury during the past twelve months in sports club members

\begin{tabular}{|c|c|c|c|c|c|c|c|c|c|}
\hline \multirow[b]{3}{*}{ Training Characteristics } & \multirow{2}{*}{\multicolumn{3}{|c|}{ All $(n=1077)$}} & \multicolumn{3}{|c|}{ Sports club members } & \multirow{2}{*}{\multicolumn{3}{|c|}{ Girls $(n=528)$}} \\
\hline & & & & \multicolumn{3}{|c|}{ Boys $(n=549)$} & & & \\
\hline & $\overline{\mathrm{OR}^{*}}$ & $95 \% \mathrm{Cl}$ & $P$ Value\# & $\overline{O R}$ & $95 \% \mathrm{Cl}$ & $P$ Value ${ }^{\S}$ & $\overline{O R}$ & $95 \% \mathrm{Cl}$ & $P$ Valuex \\
\hline \multicolumn{10}{|l|}{ Main sports } \\
\hline Team and contact sports & 1.0 & & & 1.0 & & & 1.0 & & \\
\hline Individual sports & 0.88 & $0.66-1.18$ & 0.401 & 0.99 & $0.62-1.58$ & 0.981 & 0.81 & $0.56-1.19$ & 0.288 \\
\hline \multicolumn{10}{|l|}{ Starting training (age) } \\
\hline 4-7 years old & 1.0 & & & 1.0 & & & 1.0 & & \\
\hline $8-11$ years old & 0.93 & $0.70-1.23$ & 0.595 & 0.73 & $0.49-1.09$ & 0.123 & 1.14 & $0.75-1.72$ & 0.549 \\
\hline $12-15$ years old & 0.77 & $0.54-1.10$ & 0.155 & 1.02 & $0.62-1.69$ & 0.923 & 0.64 & $0.38-1.07$ & 0.086 \\
\hline \multicolumn{10}{|c|}{ Active training years at least 2 times/week } \\
\hline $0-4$ years & 1.0 & & & 1.0 & & & 1.0 & & \\
\hline $5-8$ years & 1.33 & $0.99-1.79$ & 0.056 & 1.17 & $0.75-1.82$ & 0.488 & 1.49 & $1.00-2.21$ & 0.048 \\
\hline $9-11$ years & 1.02 & $0.72-1.46$ & 0.898 & 1.03 & $0.64-1.67$ & 0.894 & 0.94 & $0.55-1.63$ & 0.835 \\
\hline \multicolumn{10}{|c|}{ Training hours per week during training season } \\
\hline 3-6 h/week & 1.0 & & & 1.0 & & & 1.0 & & \\
\hline 7-14 h/week & 1.63 & $1.21-2.18$ & 0.001 & 1.91 & $1.24-2.94$ & 0.003 & 1.42 & $0.95-2.11$ & 0.088 \\
\hline $15 \mathrm{~h}$ or more/week & 1.66 & $1.11-2.50$ & 0.014 & 2.14 & $1.24-3.71$ & 0.007 & 1.23 & $0.66-2.30$ & 0.513 \\
\hline \multicolumn{10}{|c|}{ Training hours per week during competition season } \\
\hline $3-6 \mathrm{~h} /$ week & 1.0 & & & 1.0 & & & 1.0 & & \\
\hline 7-14 h/week & 1.48 & $1.10-1.98$ & 0.009 & 1.64 & $1.08-2.49$ & 0.021 & 1.33 & $0.88-2.01$ & 0.173 \\
\hline $15 \mathrm{~h}$ or more/week & 1.97 & $1.32-2.94$ & 0.001 & 2.26 & $1.31-3.90$ & 0.003 & 1.68 & $0.92-3.05$ & 0.091 \\
\hline \multicolumn{10}{|c|}{ The amount of competitions during last 12 months } \\
\hline 7-19 competitions & 1.0 & & & 1.0 & & & 1.0 & & \\
\hline 20-39 competitions & 1.39 & $0.96-2.02$ & 0.085 & 1.21 & $0.71-2.06$ & 0.492 & 1.60 & $0.95-2.71$ & 0.080 \\
\hline 40 competitions or more & 1.53 & $1.02-2.30$ & 0.038 & 1.42 & $0.83-2.41$ & 0.197 & 1.57 & $0.81-3.05$ & 0.178 \\
\hline \multicolumn{10}{|c|}{ Resting days per week during training season } \\
\hline 3 resting days/week & 1.0 & & & 1.0 & & & 1.0 & & \\
\hline 2 resting days/week & 1.15 & $0.80-1.65$ & 0.448 & 1.07 & $0.64-1.77$ & 0.807 & 1.25 & $0.75-2.08$ & 0.400 \\
\hline 1 resting day/week & 1.21 & $0.84-1.75$ & 0.312 & 1.30 & $0.78-2.18$ & 0.312 & 1.11 & $0.66-1.88$ & 0.689 \\
\hline 0 resting day/week & 1.17 & $0.44-3.16$ & 0.750 & 1.30 & $0.34-4.89$ & 0.702 & 1.04 & $0.23-4.59$ & 0.961 \\
\hline
\end{tabular}

* OR = Odds Ratio, $95 \% \mathrm{Cl}=95 \%$ Confidence Interval

\# $P$ Values in all sports club members derived from logistic regression adjusted for sex

${ }^{5} P$ Values in boys derived from logistic regression

a $P$ Values in girls derived from logistic regression

was 7.8 fold $(P=0.007)$ and for those who reported "7 h or more physical activity per week" it was 20.3 fold $(P<0.001)$ compared to those who reported "no physical activity". When we included sports club participation in the model the sex-adjusted probability for reporting an acute injury for those non-members who reported " $7 \mathrm{~h}$ or more physical activity per week" was 10.1 fold $(P=0.002)$ and for those who participated in sports clubs it was 2.4 fold $(P<0.001)$ (Additional file 7: Table S7).

The probability of reporting an overuse injury for those who reported "physical activity for about $30 \mathrm{~min}$ per week" was 3.7 fold $(P=0.045)$ compared to those not reporting any physical activity and the likeliness increased with increasing physical activity. For those who reported " $7 \mathrm{~h}$ or more physical activity per week" it was 9.8 fold $(P<0.001)$ compared to those who reported "no physical activity". When we included sports club participation in the model the sex-adjusted probability for reporting an overuse injury for those non-members who reported " $7 \mathrm{~h}$ or more physical activity per week" was 6.5 fold higher $(P=0.002)$ and for those who participated in sports clubs it was 1.7 fold higher $(P<0.001)$ (Additional file 7: Table S7). 


\section{Discussion}

Sixty percent of sports club members and $30 \%$ of non-members reported at least one acute or overuse injury during the past twelve months. The probability for sustaining an acute or overuse injury increased with the increasing number of training hours and competitions among sports club members. However, having less than three resting days per week did not increase an injury. Acute injuries were reported more often in contact and team sports than in individual sports among sports club members.

The sports club members and non-members formed a representative sample of the different regions of Finland and the sports club sample covered the 10 most popular sports in Finland. Both individual and team sports and summer and winter sports were equally represented [28]. Both groups should have similar accuracy in injury data and recall. The terms "acute injury" and "overuse injury" were defined in the questionnaire-as validated earlier $[19,25,26]$ - to make the answers more reliable, and acute and overuse injuries were looked at separately.

One limitation of our study is the cross-sectional nature of this study. Also the self-reported questionnaire may cause recall bias and sports club members may remember their injury history better. However, the questionnaires used in these surveys were compiled from previously validated questions [19, 23-26]. The non-respondents were 9th grade students as were those who took part in the study, we do not have further details concerning the non-respondents. We believe that the risk for either participating or not participating is the same for both injured and non-injured adolescents. However, there may be a risk that injured athletes had withdrawn themselves from sports club activities because of an injury/injuries and would be non-members with an injury sustained in a sports club setting. Although, at the age of 15 only a few injuries are so severe that they cause withdrawal from sports participation. There may also be a risk that sports club members understood the terms an acute and an overuse injury more clearly than non-members, but the definitions were written clearly and their differences were underlined to minimize the risk of misunderstanding. In the self-reported questionnaire there is always a risk that adolescent is not aware of the name of the anatomic location that is injures, but this is the case in the both study groups, and thus, the results should be comparable. A further limitation is that training details were only inquired from the sports club member group, since reporting training hours may have a different meaning and be less valid among non-members. We also carried out an additional analysis of the occurrence of injuries in both sports club members and non-members using an identical question on leisure-time physical activity volume for both groups.

\section{Injury occurrence and profile}

Different sports disciplines have their specific typical acute and overuse injuries. For optimal preventive measures, sports-specific injury profiles need to be known. Taking into account the intensity and type of sports performed by the Finnish adolescents, our results concerning athletic injuries in young people who are participating in sports are in line with previous findings [6, 29-32].

Leppänen et al. [6] studied overuse injuries among adolescent basketball and floorball players using a self-reported questionnaire. Among floorball players the knee was the most common site for an overuse injury, the same finding was made in our study. Bostrom et al. [29] studied seven different sports and found that nearly half of the young adults had been injured during the past 12 months, which is close to $44 \%$ of adolescents having sustained at least one acute injury in our study. In both studies boys were more often injured than girls. However, in the study by Bostrom et al. [29] an acute injury was defined by an absence time of one week from sports compared to one day in our study. In a study of high school athletes by Kahlenberg et al. [30] those with a higher total number of hours per year of sports participation had a higher risk of injury. In our study, both acute and overuse injury was significantly increased with 15 $\mathrm{h}$ or more of training per week.

In our study, the acute injury incidence rate was significantly higher in team and contact sports compared to individual sports, which is in accordance with previous studies [4, 5, 33, 34], and acute injuries occurred more frequently to boys than to girls. This reflects the sports type distribution among Finnish adolescents, which explains why this result deviates from the findings seen in specific sports with a similar degree of competitiveness, where girls have a higher incidence of injury than boys [35-37]. In our study individual sports that were more often performed by girls were orienteering, riding, dancing, gymnastics, and skating.

In our study, sports club members reported on average one overuse injury per year. This was more than in non-members, but the reported 0.7 overuse injuries per year among non-members also needs to be recognized. Our result is in line with that reported by Malisoux et al. [31], but again the risk for an overuse injury depends on the sport type [6].

The most common acutely injured location for both sports club members and non-members was the wrist and hand combined. The most common more specific location among sports club members were the ankle and foot, again in accordance with previous research [35, 38]. In our study, the most common site for an overuse injury was the knee for sports club members and the wrist and hand for non-members. 
Earlier studies have reported that the knee is commonly injured in adolescents [39] and 18-35 year old adults [40] especially in ball games and running. The knee was second most common acute injury location in non-members whereas in sports club members it was the 5th most common injury location. Acute knee injuries may be relatively less common among sports-club members as a result of neuromuscular training targeted at injury prevention [41]. Acute knee injuries were reported by $12 \%$ of all participants, there was no difference between boys and girls but a greater number of acute knee injuries were reported by sports club members than non-members. Most acute knee injuries occurred in ball games and among girls in synchronized skating and gymnastics. In a previous study by Pasanen et al. [42] $18 \%$ of acute injuries in floorball were knee injuries, including 7 ACL injuries. In our study no ACL injuries were reported. None of the knee injuries reported in our study required more than three days away from normal training or competition, so we can assume they were minor injuries.

In our study $12 \%$ of overuse injuries were knee injuries, significantly more of these were reported by sports club members. In previous studies it has also been found that Osgood-Schlatter disease, patellofemoral pain, and other unspecified knee pain are common in adolescents participating in sports [43-45]. Leppänen et al. [46] found in previous study of overuse injuries in basketball and floorball players that $35 \%$ of overuse injuries were injuries of the knee, however the age group in this study was $12-20$ years. In our study knee overuse injuries were most common in ball game players.

In line with previous research $[35,47,48]$ the most common acute injury type in both groups was sprains followed by contusions or bruises. The most common type of overuse injury was muscle injury in both groups. This injury type includes, for example, chronic exertional compartment syndrome and delayed onset muscle soreness. However, it can be argued whether delayed onset muscle soreness (DOMS) should be classified as an overuse injury. DOMS is primarily caused by eccentric contractions that produce the greatest muscle tension [49]. Sports club members reported significantly more overuse injuries of the bone tissue than non-members. Included in these injuries may be, for example, Osgood-Schlatter disease. Stress fractures were not statistically significantly more common in sports club members. A potential cause for this may be that this type of injury may have caused withdrawal from sports club activities. Also only a small minority of sports club participants participated in intensive elite level training. Many earlier studies have found that participation in gymnastics, dance, and other high-impact activity carries a higher risk for stress fractures, especially in girls $[50,51]$.

\section{Injury circumstances and the need for prevention}

The injury risk varies between different sports and other leisure time activities [52]. In accordance with earlier research $[3,35,53]$ organized training was found to be the most common setting for acute injuries in sports club members, followed by matches or competitions. However, the injury risk is not always higher in organized sports. Monroe et al. [13] found that players taking part in organized soccer had a higher prevalence of injury compared to players of non-organized soccer. On the contrary, in basketball non-organized players had a higher prevalence of injury compared to players of organized basketball [13].

McQuillan and Campbell [34] reported that sports caused $32 \%$ of the injuries in 12-17-year-old adolescents. In non-members, most acute injuries occurred during leisure time. Abernethy and MacAuley [54] reported that $51 \%$ of accidental injuries occur during school sports, which was much more than in our study. In addition to formal physical education class, school sports included organized and casual sports performed at school. Although sports club members may have better balance because of their more versatile training methods, this does not cause a difference in the amount of injuries in school sports. This may be due to sports club members participating more intensively in school sports compared to non-members. The most frequently reported cause for an acute injury was falling or stumbling in both groups. Sports club members were more likely than non-members to sustain acute injuries in tackling situations. This can be explained by the high participation rate in team and contact sports [55].

Earlier studies have reported that greater sports participation is associated with an increased risk of injury both in adolescents and adults $[19,56]$. In accordance with the results of our study, Richmond et al. [57] found that adolescents had a greater risk of a sports-related injury with increasing hours of play. In our study, training details were inquired only from sports club members, and we found that weekly training for over seven hours was associated with a higher amount of acute injuries in boys and girls. However, the amount of overuse injuries was significantly increased only among boys when training over seven hours per week. It has also been found that low levels of habitual physical activity increase the injury risk in children when exposure time is taken into account [58]. As reported earlier [4], the number of competitions is associated with the yearly incidence of injury, particularly in team games. In our study, boys reported having taken part in twice as many competitions during the preceding year than girls did.

We also surveyed the leisure-time physical activity from both groups. Only $30 \mathrm{~min}$ of weekly physical 
activity was found to significantly increase the likeliness of both the acute and overuse injuries. Injuries were further increased with increasing leisure-time physical activity in those completing $2 \mathrm{~h}$ or more of physical activity per week. This was seen more clearly in sports club members. This result is in agreement with previous research showing that more competitive forms of physical activity are associated with higher injury risk. [59, 60].

Effective preventive measures targeted at risk factors for both acute and overuse injuries are needed in both organized and non-organized sports in order to prevent injuries. Poor knee alignment and control during jump-landing may increase the risk of injury. However, these risk factors does not seem to change in young athletes by time by simply playing the sport. Improvement of knee stability needs specific neuromuscular exercises [39].

Physical activity programs that develop strength and proprioception have been shown to be effective in preventing acute and overuse sports injuries [61, 62]. Including this type of training as a part of physical education would also aid adolescents not participating in sports club activities to meet physical activity guidelines without injuries [63, 64].

\section{Conclusions}

Physical activity provides a balance to the nowadays common sedentary lifestyle common among adolescents. Our study shows the quantity of the combined extent of acute and overuse injuries among adolescent sports club members compared to non-members. The sports type, such as team and contact sports, training, and competing habits influence this among adolescents. Injury prevention is needed, both in organized and non-organized sports.

\section{Additional files}

\section{Additional files 1: Table S1. Main sports reported by sports club} members. (DOC $61 \mathrm{~kb}$ )

Additional files 2: Table S2. The main structured questions in the questionnaire. (DOC $43 \mathrm{~kb}$ )

Additional files 3: Table S3. Anatomical site of at least one acute injury in boys and girls among sports club members and non-members. (DOC $70 \mathrm{~kb}$ )

Additional files 4: Table S4. Anatomical site of at least one overuse injury in boys and girls among sports club members and non-members. (DOC $67 \mathrm{~kb}$ )

Additional files 5: Table S5. Comparison of at least one acute or overuse injury in sports club members (training three times or more per week during the training season) and non-members in the past twelve months. (DOC $62 \mathrm{~kb}$ )

Additional files 6: Table S6. Reported leisure-time physical activity volumes among sports club members and non-members. (DOC $50 \mathrm{~kb}$ )
Additional files 7: Table S7. Odds ratios for the occurrence of acute and overuse injury (at least one injury) by sports club participation and by volume of reported leisure-time physical activity derived from logistic regression analysis adjusted for sex. (DOC $62 \mathrm{~kb}$ )

\section{Abbreviations}

ACL: Anterior cruciate ligament; Cl:: Confidence Interval; DOMS: Delayed onset muscle soreness; FHPSC: The Finnish Health Promoting Sports Club (FHPSC); OR: Odds ratio

\section{Acknowledgements}

The authors wish to thank all the participating sports clubs and their officials and coaches. The authors also thank the participating schools for their assistance in the surveys. Without all the adolescents who participated in the study, this research would not have been possible. The authors want to express their gratitude to these youth.

\section{Funding}

This study was funded by the Finnish Ministry of Education and Culture (grant number: 6/091/2011). The funding bodies had no role in the design of the study, collection, analysis, interpretation of data or in writing the manuscript.

\section{Availability of data and materials}

The datasets generated and/or analysed during the current study are not publicly available but are available from the corresponding author on reasonable request.

\section{Authors' contributions}

All authors (LR, KT, JP, SK, LA, OH, RK, KS, HS, TV, LK, JV, UK) contributed to study conception and design. SK and JP coordinated and managed all parts of the study. LR and KT carried out the literature search. SK and JV conducted data collection and performed preliminary data preparations. LR, KT and JV conducted data analyses and all the authors contributed to the interpretation of data. LR, KT, UK and JP wrote the first draft of the paper and all authors provided substantive feedback on the paper and contributed to the final manuscript. All authors have approved the submitted version of the manuscript. JP is the guarantor.

\section{Ethics approval and consent to participate}

The Ethics Committee of Health Care District of Central Finland was received (record number 23 U/2012). All sports clubs participated free-willingly to the study. This was secured by requesting clubs permission at the beginning of study and by written informed consent from the participating youth for the questionnaire. Written consent on behalf of participants below the age of 16 was obtained from the parental/legal guardian. Thereafter, all respondents were notified that they had a right to refuse to participate and withdraw from the study at any time.

\section{Consent for publication}

Not applicable.

\section{Competing interests}

The authors declare that they have no competing interests.

\section{Publisher's Note}

Springer Nature remains neutral with regard to jurisdictional claims in published maps and institutional affiliations.

\section{Author details}

${ }^{1}$ Orton Orthopaedic Hospital, Orton, Helsinki, Finland. ${ }^{2}$ Tampere Research Center of Sports Medicine, Tampere, Finland. ${ }^{3}$ Faculty of Sport and Health

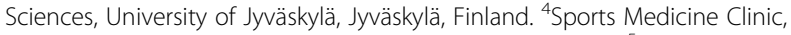
Foundation for Sports and Exercise Clinic, Helsinki, Finland. ${ }^{5}$ Paavo Nurmi Centre \& Department of Physical Activity and Health, University of Turku, Turku, Finland. ${ }^{6}$ Oulu Deaconess Institute, Department of Sports and Exercise Medicine, Oulu, Finland. ${ }^{7}$ Medical Research Center Oulu Oulu University Hospital and University of Oulu, Oulu, Finland. ${ }^{8}$ Center for Life Course Health Research, University of Oulu, Oulu, Finland. ${ }^{9}$ Kuopio Research Institute of Exercise Medicine, Kuopio, Finland. ${ }^{10}$ Department of Clinical Physiology and 
Nuclear Medicine, Kuopio University Hospital, Kuopio, Finland. ${ }^{11}$ Department of Psychology, University of Jyväskylä, Jyväskylä, Finland. ${ }^{12}$ UKK Institute of Health Promotion Research, Tampere, Finland.

Received: 1 March 2018 Accepted: 11 January 2019

Published online: 19 January 2019

\section{References}

1. Eime R, Young J, Harvey J, et al. A systematic review of the psychological and social benefits of participation in sport for children and adolescents: informing development of a conceptual model of health through sport. Int J Behav Nutr Phys Act. 2013;10:135. https:// doi.org/10.1186/1479-5868-10-135.

2. Hallal PC, Victora CG, Azevedo MR, et al. Adolescent physical activity and health: a systematic review. Sports Med. 2006;36(12):1019-30

3. Caine D, Maffulli N, Caine C. Epidemiology of injury in child and adolescent sports: injury rates, risk factors, and prevention. Clinics Sports Med. 2008; 27(1):19-50, vii. https://doi.org/10.1016/j.csm.2007.10.008.

4. Theisen $D$, Frisch $A$, Malisoux $L$, et al. Injury risk is different in team and individual youth sport. J Sci Med Sport. 16(3):200-4. https://doi.org/10.1016/ j.jsams.2012.07.007

5. Kujala UM, Taimela S, Antti-Poika I, et al. Acute injuries in soccer, ice hockey, volleyball, basketball, judo, and karate: analysis of national registry data. BMJ. 1995;311(7018):1465-8.

6. Leppanen M, Pasanen K, Kujala UM, et al. Overuse injuries in youth basketball and floorball. Open Access J Sports Med. 2015;6:173-9. https:// doi.org/10.2147/OAJSM.S82305

7. Stubbe $\mathrm{JH}$, van Beijsterveldt AM, van der Knaap S, et al. Injuries in professional male soccer players in the Netherlands: a prospective cohort study. J Athl Train. 2015;50(2):211-6. https://doi.org/10.4085/ 1062-6050-49.3.64

8. Abbott K. Injuries in women's ice hockey: special considerations. Curr Sports Med Rep. 2014 Nov-Dec;13(6):377-82. https://doi.org/10.1249/JSR. 0000000000000102 .

9. Soderman $\mathrm{K}$, Pietila T, Alfredson $\mathrm{H}$, et al. Anterior cruciate ligament injuries in young females playing soccer at senior levels. Scand J Med Sci Sports. 2002;12(2):65-8

10. Walden $M$, Hagglund $M$, Werner J, et al. The epidemiology of anterior cruciate ligament injury in football (soccer): a review of the literature from a gender-related perspective. Knee Surg Sports Traumatol Arthrosc. 2011; 19(1):3-10. https://doi.org/10.1007/s00167-010-1172-7.

11. Mattila V, Parkkari J, Kannus $P$, et al. Occurrence and risk factors of unintentional injuries among 12- to 18-year-old Finns--a survey of 8219 adolescents. Eur J Epidemiol. 2004;19(5):437-44.

12. Mattila VM, Parkkari J, Koivusilta L, et al. Participation in sports clubs is a strong predictor of injury hospitalization: a prospective cohort study. Scand J Med Sci Sports. 2009;19(2):267-73. https://doi.org/10.1111/j.1600-0838. 2008.00800.x.

13. Monroe KW, Thrash C, Sorrentino A, et al. Most common sports-related injuries in a pediatric emergency department. Clin Pediatr (Phila). 2011;50(1): 17-20. https://doi.org/10.1177/0009922810378735.

14. Telford RM, Telford RD, Cochrane $T$, et al. The influence of sport club participation on physical activity, fitness and body fat during childhood and adolescence: the LOOK longitudinal study. J Sci Med Sport. 2016;19(5):4006. https://doi.org/10.1016/j.jsams.2015.04.008.

15. DiFiori JP, Benjamin HJ, Brenner JS, et al. Overuse injuries and burnout in youth sports: a position statement from the American medical Society for Sports Medicine. Br J Sports Med. 2014;48(4):287-8. https://doi.org/10.1136/ bjsports-2013-093299.

16. Aira T, Kannas L, Tynjälä J. Liikunta-aktiivisuuden väheneminen murrosiässä Drop-off ilmiön aikatrendejä ja kansainvälistä vertailua WHOkoululaistutkimuksen (HBSC-Study) aineistolla 1986-2010. Miksi murrosikäinen luopuu liikunnasta? [Diminishing Physical Activity in Adolescence. The Time Trends and International Comparisons of the Dropoff Phenomena in the 1986-2010 Data of Health Behavior in School-aged Children Study. In the publication Why does adolescents give up on physical activity?]. In.: Publications of State Council of Sport.2013: 12-29.

17. Mononen K, Blomqvist M, Koski P, et al. Urheilu ja seuraharrastaminen [Sports and sports club participation]. vol. 4: State Sport Council publications. 2016:27-35
18. Kokko S, Selänne $H$, Alanko $L$, et al. Health promotion activities of sports clubs and coaches, and health behaviours in youth participating in sports clubs: the health promoting sports Club study. BMJ Open Sport Exerc Med. 2015:1(1):e000034.

19. Ristolainen $L$, Heinonen $A$, Turunen $H$, et al. Type of sport is related to injury profile: a study on cross country skiers, swimmers, long-distance runners and soccer players. A retrospective 12-month study. Scand J Med Sci Sports. 2010 Jun;20(3):384-93. https://doi.org/10.1111/j.1600-0838.2009.00955.x.

20. Arnason A, Sigurdsson SB, et al. Risk factors for injuries in football. Am J Sports Med. 2004;32(Suppl 1):S5-S16.

21. Hawkins RD, Fuller CW. A prospective epidemiological study of injuries in four English professional football clubs. Br J Sports Med. 1999;33(3):196-203.

22. Brukner $P$, Bennell K. Stress fractures in female athletes. Diagnosis, management and rehabilitation. Sports Med 1997. 1997;24(6):419-29.

23. Kokko S, Kannas L, Villberg J, et al. Health promotion guidance activity of youth sports clubs. Health Educ. 2011;111:452-63.

24. Pasanen K, Parkkari J, Pasanen M, et al. Neuromuscular training and the risk of leg injuries in female floorball players: cluster randomised controlled study. BMJ. 2008;337:a295. https://doi.org/10.1136/bmj.a295.

25. Eloranta I, Tittonen $\mathrm{T}$. The reliability and validity of sport injury questionnaire in questions concerningacute and overused injuries (in Finnish). University of Jyväskylä: Master's thesis; 2006.

26. Karhula K, Pakkanen S. 2005 The reliability and validity of sport injury questionnaire in the questionsconcerning recurrent and career-ending injuries (in Finnish). Master's thesis, University of Jyväskylä. Available at http://urn.fi/URN:NBN:fi:jyu-2005378.

27. Mäkelä K, Kokko S, Kannas L, et al. Physical activity, screen time and sleep among youth participating and non-participating in organized sports - the Finnish health promoting sports Club (FHPSC) study. Adv Phys Educ. 2016;4:378-88.

28. Kokko S, Kannas L, Villberg J. The health promoting sports club in Finland--a challenge for the settings-based approach. Health Promot Int. 2006;21(3): 219-29.

29. Bostrom A, Thulin K, Fredriksson M, et al. Risk factors for acute and overuse sport injuries in Swedish children 11 to 15 years old: what about resistance training with weights? Scand J Med Sci Sports. 2016;26(3):317-23. https:// doi.org/10.1111/sms.12432.

30. Kahlenberg CA, Nair R, Monroe E, et al. Incidence of injury based on sports participation in high school athletes. Phys Sportsmed. 2016:44(3):269-73. https://doi.org/10.1080/00913847.2016.1180269.

31. Malisoux L, Frisch A, Urhausen A, et al. Monitoring of sport participation and injury risk in young athletes. J Sci Med Sport. 2013;16(6):504-8. https://doi. org/10.1016/j.jsams.2013.01.008

32. Malisoux L, Frisch A, Urhausen A, et al. Injury incidence in a sports school during a 3-year follow-up. Knee Surg Sports Traumatol Arthrosc. 2013;21(12): 2895-900. https://doi.org/10.1007/s00167-012-2185-1.

33. Aman M, Forssblad M, Henriksson-Larsen K. Incidence and severity of reported acute sports injuries in 35 sports using insurance registry data. Scand J Med Sci Sports. 2016;26(4):451-62. https://doi.org/10.1111/sms.12462.

34. McQuillan R, Campbell H. Gender differences in adolescent injury characteristics: a population-based study of hospital a\&E data. Public Health. 2006;120(8):732-41.

35. Beachy G, Rauh M. Middle school injuries: a 20-year (1988-2008) multisport evaluation. J Athl Train. 2014:49(4):493-506. https://doi.org/10.4085/1062 6050-49.2.19.

36. Pierpoint LA, Williams CM, Fields SK, et al. Epidemiology of injuries in United States high school track and field: 2008-2009 through 2013-2014. Am J Sports Med. 2016;44(6):1463-8. https://doi.org/10.1177/0363546516629950.

37. Rauh MJ, Margherita AJ, Rice SG, et al. High school cross country running injuries: a longitudinal study. Clin J Sport Med. 2000;10(2):110-6.

38. Orr $\mathrm{R}$, Cheng $\mathrm{HL}$. Incidence and characteristics of injuries in elite Australian junior rugby league players. J Sci Med Sport. 2016;19(3):212-7. https://doi. org/10.1016/j.jsams.2015.03.007.

39. Leppanen M, Pasanen K, Kulmala JP, et al. Knee control and jump-landing technique in Young basketball and Floorball players. Int J Sports Med. 2016; 37(4):334-8. https://doi.org/10.1055/s-0035-1565104.

40. Wirtz AD, Willson JD, Kernozek TW, et al. Patellofemoral joint stress during running in females with and without patellofemoral pain. Knee. 2012;19(5): 703-8. https://doi.org/10.1016/j.knee.2011.09.006.

41. Hubscher M, Zech A, Pfeifer $K$, et al. Neuromuscular training for sports injury prevention: a systematic review. Med Sci Sports Exerc. 2010;42(3):413-21. https://doi.org/10.1249/MSS.0b013e3181b88d37. 
42. Pasanen K, Hietamo J, Vasankari T, Kannus P, Heinonen A, Kujala UM, Mattila VM, Parkkari J. Acute injuries in Finnish junior floorball league players. J Sci Med Sport. 2018;21(3):268-73. https://doi.org/10.1016/j.jsams.2017.06.021.

43. Frisch A, Croisier JL, Urhausen A, et al. Injuries, risk factors and prevention initiatives in youth sport. Br Med Bull. 2009;92:95-121. https://doi.org/10. 1093/bmb/ldp034.

44. Kujala UM, Kvist M, Heinonen O. Osgood-Schlatter's disease in adolescent athletes. Retrospective study of incidence and duration. Am J Sports Med. 1985;13(4):236-41.

45. Kujala UM, Kvist M, Osterman K. Knee injuries in athletes. Review of exertion injuries and retrospective study of outpatient sports clinic material. Sports Med. 1986;3(6):447-60

46. Leppänen M, Pasanen K, Kannus P, Vasankari T, Kujala UM, Heinonen A, Parkkari J. Epidemiology of overuse injuries in youth team sports: a 3-year prospective study. Int J Sports Med. 2017;38(11):847-56. https://doi.org/10. 1055/s-0043-114864

47. Dorje C, Gupta RK, Goyal S, et al. Sports injury pattern in school going children in union territory of Chandigarh. J Clin Orthop Trauma. 2014;5(4): 227-32. https://doi.org/10.1016/j.jcot.2014.07.004

48. Giannotti M, Al-Sahab B, McFaull S, et al. Epidemiology of acute soccer injuries in Canadian children and youth. Pediatr Emerg Care. 2011;27(2):815. https://doi.org/10.1097/PEC.0b013e3182094340.

49. Flores DV, Mejía Gómez C, Estrada-Castrillón M, Smitaman E, Pathria MN. MR Imaging of Muscle Trauma: Anatomy, Biomechanics, Pathophysiology, and Imaging Appearance. Radiographics. 2018;38(1):124-48. https://doi.org/10. 1148/rg.2018170072.

50. Sonneville KR, Gordon CM, Kocher MS, et al. Vitamin d, calcium, and dairy intakes and stress fractures among female adolescents. Arch Pediatr Adolesc Med. 2012;166(7):595-600. https://doi.org/10.1001/archpediatrics.2012.5.

51. Tenforde AS, Sayres LC, McCurdy ML, et al. Identifying sex-specific risk factors for stress fractures in adolescent runners. Med Sci Sports Exerc. 2013; 45(10):1843-51. https://doi.org/10.1249/MSS.0b013e3182963d75.

52. Parkkari J, Kannus $P$, Natri $A$, et al. Active living and injury risk. Int J Sports Med. 2004;25(3):209-16.

53. Feddermann-Demont $N$, Junge $A$, Edouard $P$, et al. Injuries in 13 international athletics championships between 2007-2012. Br J Sports Med. 2014;48(7):513-22. https://doi.org/10.1136/bjsports-2013-093087.

54. Abernethy L, MacAuley D. Impact of school sports injury. Br J Sports Med. 2003;37(4):354-5.

55. Spinks AB, Macpherson AK, Bain C, et al. Injury risk from popular childhood physical activities: results from an Australian primary school cohort. Inj Prev. 2006;12(6):390-4.

56. Michaud PA, Renaud A, Narring F. Sports activities related to injuries? A survey among 9-19 year olds in Switzerland. Inj Prev. 2001;7(1):41-5.

57. Richmond SA, Kang J, Emery CA. Is body mass index a risk factor for sport injury in adolescents? J Sci Med Sport. 2013;16(5):401-5. https://doi.org/10. 1016/j.jsams.2012.11.898.

58. Bloemers F, Collard D, Paw MC, et al. Physical inactivity is a risk factor for physical activity-related injuries in children. Br J Sports Med. 2012;46(9):66974. https://doi.org/10.1136/bjsports-2011-090546.

59. DiStefano LJ, Dann CL, Chang CJ, Putukian M, Pierpoint LA, Currie DW Knowles SB, Wasserman EB, Dompier TP, Comstock RD, Marshall SW, Kerr $Z Y$. The first decade of web-based sports injury surveillance: descriptive epidemiology of injuries in US high school Girls' soccer (2005-2006 through 2013-2014) and National Collegiate Athletic Association Women's soccer (2004-2005 through 2013-2014). J Athl Train. 2018:53(9):880-92. https://doi. org/10.4085/1062-6050-156-17.

60. Kerr ZY, Putukian M, Chang CJ, DiStefano LJ, Currie DW, Pierpoint LA, Knowles SB, Wasserman EB, Dompier TP, Comstock RD, Marshall SW. The first decade of web-based sports injury surveillance: descriptive epidemiology of injuries in US high school Boys' soccer (2005-2006 through 2013-2014) and National Collegiate Athletic Association Men's soccer (20042005 through 2013-2014). J Athl Train. 2018;53(9):893-905. https://doi.org/ 10.4085/1062-6050-166-17.

61. Lauersen JB, Bertelsen DM, Andersen LB. The effectiveness of exercise interventions to prevent sports injuries: a systematic review and metaanalysis of randomised controlled trials. Br J Sports Med. 2014;48(11):871-7. https://doi.org/10.1136/bjsports-2013-092538.

62. Olsen OE, Myklebust G, Engebretsen L, et al. Exercises to prevent lower limb injuries in youth sports: cluster randomised controlled trial. BMJ. 2005; 330(7489):449.
63. Richmond SA, Kang J, Doyle-Baker PK, et al. A school-based injury prevention program to reduce sport injury risk and improve healthy outcomes in youth: a pilot cluster-randomized controlled trial. Clin J Sport Med. 2016;26(4):291-8. https://doi.org/10.1097/JSM.0000000000000261.

64. Royall P, Troiano R, Johnson M, et al. Physical Activity Guidelines for Americans. In.: U.S. Department of Health and Human Services; 2008.

\section{Ready to submit your research? Choose BMC and benefit from:}

- fast, convenient online submission

- thorough peer review by experienced researchers in your field

- rapid publication on acceptance

- support for research data, including large and complex data types

- gold Open Access which fosters wider collaboration and increased citations

- maximum visibility for your research: over $100 \mathrm{M}$ website views per year

At BMC, research is always in progress.

Learn more biomedcentral.com/submissions 